\title{
Por um teatro da palavra transfigurada
}

\section{Fernando Matos Oliveira}

\author{
Rui Pina Coelho, Casa da Comédia (1946- \\ 1975): Um palco para uma ideia de teatro, \\ Lisboa, IN-CM, 2009, 325 pp.
}

0 desencontro entre o teatro português e a modernidade é assunto frequentemente revisitado, com particular acuidade na primeira metade do séc. $X X$, periodo que de certa forma consagra e aprofunda a diferenciação do teatro relativamente às outras artes. 0 facto de esse momento coincidir com a emergência do cinema e com os movimentos modernistas confere outra visibilidade e outro dramatismo tanto à questão crítica da autonomia do teatro enquanto arte dotada de procedimentos próprios, como à sua relação com as questões de âmbito material e social. É este confronto entre o esteticismo modernista e a pressão heterónoma exercida por empresários e pelo público sobre o teatro, que por esta altura se reedita de modo especialmente agudo.

O livro de Rui Pina Coelho, intitulado Casa da Comédia (1946-1975). Um palco para uma ideia de teatro, sendo fundamentalmente um estudo de caso, persegue na sua primeira parte de modo invulgarmente sistemático a linhagem afirmativa e autónoma da cena entre nós. Os dois capitulos iniciais analisam a "formação" do ideário que haveria de enquadrar o trajecto da Casa da Comédia, recorrendo a um léxico que não deixa de traduzir a respiração modesta em geral atribuída à nossa modernidade teatral. 0 uso de expressões como "indicadores de uma inquietação", "tímidos indícios" ou "ideário de um mo(vi)mento" ilustra as várias versões deste estado de coisas.

A narrativa do encontro intermitente com o moderno organiza-se, assim, entre o levantamento dos "precursores" e a genealogia das "experiências" teatrais subsequentes. No grupo dos pioneiros contam-se iniciativas como o Teatro Livre, o Teatro Moderno, o Teatro da Natureza, Juvénia e Teatro Novo. 0 segundo grupo alinha colectivos que de algum modo prosseguiram este caminho, mas agora com uma componente reflexiva que se traduziria num processo ascendente de capacitação critica, visível no trabalho do Teatro-Estúdio do Salitre, no Grupo Dramático Lisbonense ou no Teatro Experimental do Porto. Se a estes nomes juntarmos os Companheiros do Pátio das Comédias, o Grupo de Teatro Experimental e o Teatro d'Arte de Lisboa, eis como o livro de Rui Pina Coelho quase totaliza a narrativa do novo entre nós, no período anterior a 1974. As tentativas de adiantar a reforma da cena portuguesa seriam conduzidas justamente por personalidades como Fernando Amado, com o objectivo concreto de sintonizar o teatro com a arte e não tanto com os interesses imediatos do gosto dominante.

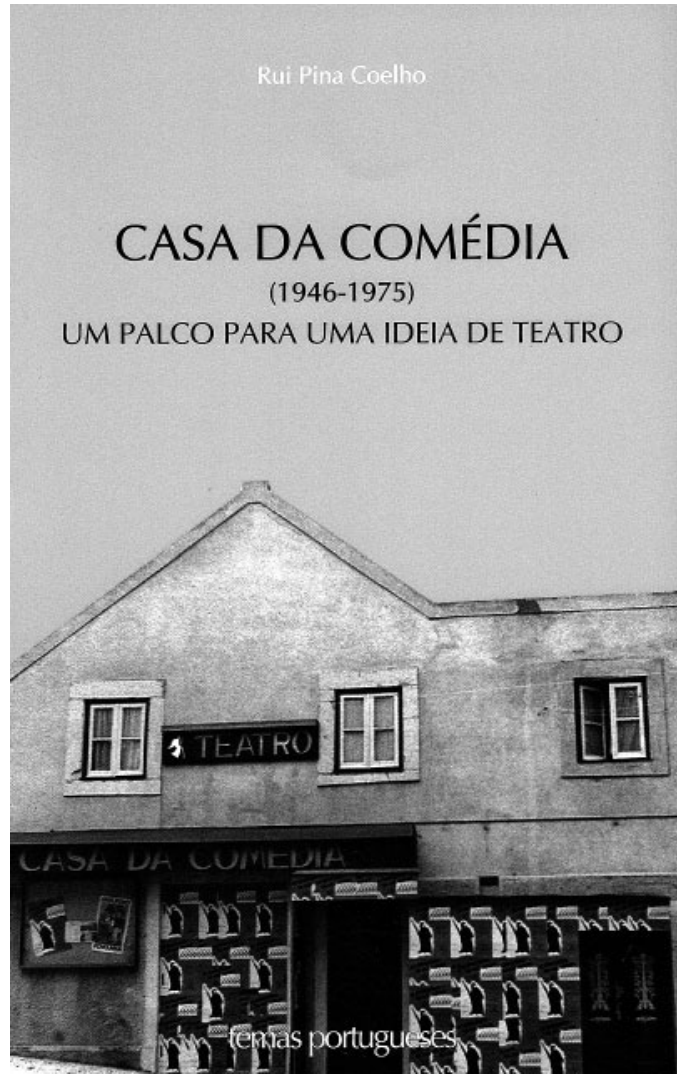

A primeira parte deste estudo encerra com uma secção intitulada "O ideário de um mo(vi)mento", oportunidade para uma síntese do esforço de renovação da actividade teatral em Portugal na primeira metade do séc. XX. Chegado a este ponto, o autor coloca-se em posição privilegiada para esclarecer, enfim, o sentido histórico do "experimentalismo" que a crítica tende a associar aos movimentos de renovação, precisando de forma reveladora o conceito e a sua propriedade descritiva. Mais do que um gesto de experimentalismo radical, como se poderia hoje imaginar, trata-se sobretudo de nomear o trabalho de todos quantos pretenderam "fazer teatro com seriedade", como se depreende da seguinte conclusão: "A busca da simplicidade formal, a moralização da classe profissional, a não subjugação a interesses comerciais, a reivindicação da figura do encenador, a subordinação ao texto, intuitos didácticos, o regresso à essência do teatro, tudo isto enquadra os projectos experimentais que tentam pôr o teatro português a par com o moderno teatro europeu" (p. 88).

Este é também o contexto da cultura teatral que caracteriza o trajecto de Fernando Amado, tema abordado 
na segunda parte do estudo. Abre-a um capítulo sobre o "ideário teatral" do encenador, tal como se apresenta delineado na obra ensaística conhecida (entretanto reunida no volume intitulado $\dot{A}$ boca de cena) e na sua escrita dramática de cariz metateatral, com destaque para A caixa de Pandora, justamente entendida como uma "peçamanifesto". A influência de Pirandello, tão impressiva em inúmeros autores deste periodo, entre Almada Negreiros, João Pedro de Andrade e José Régio, explicita em Fernando Amado não apenas a referida "reivindicação" de modernidade, mas ainda o desejo de pensar o teatro e a sua forma de comunicação; a metateatralidade é sempre de algum modo um sinal de reflexão sobre o teatro enquanto aparato expressivo, ou seja, sobre o medium propriamente dito.

A Caixa de Pandora demoniza portanto todas as formas de mercantilismo teatral, afirmando a liberdade do teatro e a sua fidelidade única à arte. Fernando Amado entende que a defesa da palavra encenada e da autonomia do teatro relativamente aos interesses comerciais seria reconhecida pelo público, a quem vinha sendo negado o contacto verdadeiro com a imaginação. Num interessante diálogo com Almada Negreiros, publicado originalmente em 1951, apesar de reconhecer a existência de "amadores de boa-vontade", culpa o público pelo alheamento em relação à arte moderna e censura os críticos pela falência da sua função mediadora, necessária à compreensão da arte contemporânea (cf. Amado 1999: 57-87). Mas o caminho a cumprir para o reencontro com a arte, nomeadamente com a arte do teatro, apenas se poderia cumprir, de facto, por via da experiência e da convivência persistente com o palco, sem mais concessões.

Como Rui Pina Coelho bem demonstra nesta monografia, a Casa da Comédia é precisamente o espaço que Fernando Amado concebeu para oficiar o teatro, para acolher e celebrar a conversão dos amadores que se pretendia multiplicar. Apresentada pela primeira vez de modo sistemático, esta missão cumpre-se diversamente ao longo das três fases em que se estrutura a vida da Casa da Comédia: a experiência inaugural no Teatro do Ginásio (1946-1947); o período áureo sob a direcção artística de Fernando Amado (1962-1965); a abertura posterior do projecto original, beneficiando da colaboração de nomes que haveriam de contribuir para o avanço do teatro independente português até à Revolução (1966-1975).

Ao longo deste período, o posicionamento teatral de Fernando Amado confirma-se a cada texto, prólogo ou encenação. 0 privilégio da "palavra transfigurada" manifesta-se ainda a cada opção de reportório, como é manifestamente o caso do texto incluido no "Programa da Temporada Inaugural de A Casa da Comédia", onde a figura oracular de Pascoais testemunha a sintonia de Amado com a transcendência da palavra e com a sobredeterminação autoral do Poeta, tomado no seu sentido clássico, como estando acima dos géneros e dos discursos. É este regime de superintendência da palavra escrita que o faz desmerecer escolas e tendências, numa atitude próxima do modernismo presencista, que colocava a literatura "viva" igualmente acima de toda a letra em estado de submissão mundana.

Dai que o teatro fosse para Fernando Amado muito mais do que divertimento ou púlpito arregimentado. 0 que possamos chamar função social do teatro radica, como sugere Rui Pina Coelho, num humanismo fundacional que tende a praticar a "apologia explícita da arte e da cultura" (p. 129). Da leitura deste volume dedicado à Casa da Comédia sobressai o entendimento do teatro como celebração humana, apontando para o reencontro essencial com as coisas do espírito. Ao verbo transparente do chamado "teatro de bilheteira", opõe-se assim a prosa resistente e misteriosa do Verbo escuro que encena na temporada de 1963. Data também deste ano a reflexão dedicada "Aos que amam o teatro", ocasião para o encenador nos adiantar uma breve e rara confissão programática: "Queremos contribuir (veja-se nisto um programa) para que de facto o texto duma obra teatral mereça o título que tecnicamente em toda a parte o define: Poema. 0 que, de resto, bem longe de pressupor devaneio, evasão, implica ao contrário a necessidade da expressão dramática directa, entre risos e prantos..." (Amado 1999:180).

0 livro encerra com mais de uma centena de páginas de natureza documental, reunindo todo o repertório da Casa da Comédia, respectivos textos e autores, fichas artísticas dos espectáculos, o elenco de actores que por lá passaram, bem como uma antologia fotográfica de encenações posteriores a 1962. No seu todo, este estudo de Rui Pina Coelho, além das qualidades referidas, sendo originalmente uma tese de mestrado apresentada à Fculdade de Letras da Universidade de Lisboa, faz justiça ao trabalho persistente que tem vindo a ser desenvolvido pelo Centro de Estudos de Teatro em prol da memória do teatro em Portugal.

\section{Referência bibliográfica}

AMADO, Fernando (1999), Á boca de cena, Lisboa, Et etc. 